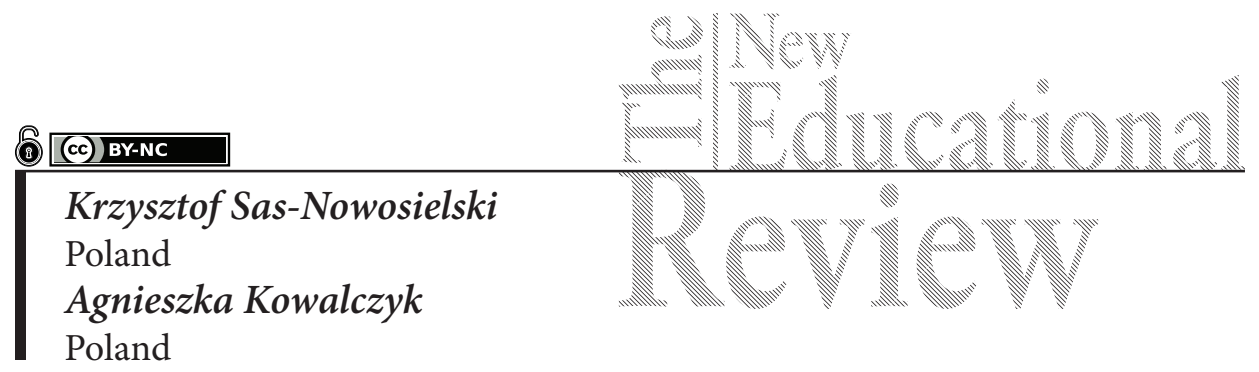

\title{
The Self-efficacy of Physical Education Teachers and Burnout in the Teaching Profession
}

DOI: 10.15804/tner.2019.58.4.14

\begin{abstract}
Teachers, including physical education (PE) teachers, are at risk of burning out in their work. The consequences of this syndrome have a negative impact on the teacher themselves and on their students. Therefore it is very important to identify factors that may prevent its occurrence. Self-efficacy is considered one such factor. The aim of the study was to determine if self-efficacy specific to PE teachers is related to their burnout. The study was conducted using a survey method, with the use of the Physical Education Teaching Efficacy Scale [PETES] and the Maslach Burnout Inventory. A total of 401 PE teachers were surveyed. PE teachers turned out to be rather moderately burnt out, except for one dimension - a reduced sense of personal accomplishments - which in almost the whole sample reached high values. Regression analyses conducted for all three dimensions of burnout were significant, explaining from $4 \%$ up to $10 \%$ of the variance. The dimension of accomplishments was positively predicted by two kinds of self-efficacy: applying scientific knowledge in teaching PE, and teaching students with special needs. Emotional exhaustion was significantly and negatively predicted by assessment efficacy, and using technology efficacy, and positively by accommodating skill level differences of efficacy. Finally, depersonalization was negatively predicted by instructional efficacy.
\end{abstract}

Key words: physical education teachers, burnout, self-efficacy 


\section{Introduction}

The term professional burnout refers to a "psychological syndrome of emotional exhaustion, depersonalization and reduced personal accomplishments that occur among individuals who work with other people in some capacity" (Maslach, Jackson, \& Leiter, 1996, p.192). The teaching profession is a good example among occupations, imposing so much stress on the people involved in it that burnout becomes a real and serious problem in this community (Hakanen et al., 2006). Among factors causing teachers to burn out in their jobs are difficult relationships with their pupils (disrespect, disobedience, contrariness), over-crowded classes, educational reforms which are not always favorable for teachers, parents who take too much for granted, and low salaries, to name but a few (Brudnik, 2010; Aloe et al., 2014). Physical education (PE) teachers may experience additional factors such as having a sense that their subject is of low prestige, inadequate gym space, the impetuous nature of pupils' activities, noise etc. (Brudnik, 2010; Colakoglu \& Yllmaz, 2014; Bartholomew et al., 2014). The abovementioned conditions, along with the high requirements of the teaching profession, can put teachers under severe stress that can accumulate and, with the passing of time, result in burnout. According to Maslach et al., (1996) this phenomenon involves three dimensions: emotional exhaustion, which is the expression of fatigue and the sense of professional exploitation and is manifested by irritability, mood decline, and even somatic symptoms, like headaches or insomnia; depersonalization, the essence of which is an indifferent, heartless, dehumanized, unsentimental, or even negative attitude to pupils; and reduced personal accomplishment, or downgrading one's own capabilities, lowered perceptions of competence and lack of satisfaction within professional accomplishments. The situation in which a person manifests simultaneously a high level of emotional exhaustion, a high level of depersonalization and a significant reduction in the sense of personal accomplishments is considered as a full-symptom burnout. Taking into consideration the serious consequences of burnout, both for the teachers themselves and for the pupils in their charge, it is important to investigate causes of the phenomenon indicated and ways to prevent it.

Among psychological factors that can make teachers more resilient to burnout self-efficacy is being considered. This notion was proposed by Bandura (1997) to describe beliefs that one possesses "capabilities to organize and execute the courses of action required to produce given attainments" (p.3). As self-efficacy is domain, and even context, specific, in the context of the teaching profession it may be conceptualized as teachers' "beliefs in their own ability to plan, organize and carry 
out activities which are required to attain educational goals" (Skaalvik \& Skaalvik, 2010: p. 1059). As such, it not only has an effect on the educational goals one sets for oneself, one's motivation in challenging situations, the level of effort put into educational tasks, or one's persistence in difficult situations (Savaş, Bozgeyik, \& Eser, 2014; Oakes, 2013), but can also be related to burnout (Skaalvik \& Skaalvik 2010; Brown 2012; Oakes 2013; Savaş, Bozgeyik \& Eser, 2014).

Brown (2012) suggests, in her review of studies on teachers' self-efficacy and teacher burnout, that high efficacy beliefs are an "important stress resource factor in mitigating teacher burnout" and that teachers possessing them "may perceive the objective demands of daily teaching as being less threatening than those teachers who harbor self-doubts about their professional performance. Being able to manage stressful demands could prevent the emergence of teacher burnout" (p. 49). However, most empirical evidence on the relationship between self-efficacy and burnout originates from studies of teachers working in contexts other than PE. Since, referring to Bandura's self-efficacy theory, mentioned earlier, this construct is specific to the context and situations, then measures of self-efficacy should also be tailored to the specificity of the job demands of PE teachers, which are quite different from math, history or language teachers. Firstly, PE teachers work in a unique environment(-s) - the gym, the swimming pool, the sports field. Secondly, activities they teach are more dynamic, spontaneous and impetuous. These - and other - characteristics of PE classes allow children to blow off steam, to find physical fulfillment, to express emotions, to shout out, but at the same time create enormous stress and challenge for PE teachers. As a consequence, factors that may cause burnout, as well as those which should constitute a sense of efficacy in meeting the challenges of PE lessons, need specific reflection. Taking the abovementioned factors into consideration, the purpose of the study was to explore if and how PE teachers' burnout and their self-efficacy in PE were related.

\section{Methodology of Research}

\section{Research Sample}

In total $401 \mathrm{PE}$ teachers working in schools in Katowice and neighboring cities were surveyed (including 177 women), aged $40.52 \pm 9.11$ years.

\section{Instrument and Procedures}

They filled in two questionnaires: 1/ Maslach Burnout Inventory (MBI) (Pasikowski, 2000) and 2/ Physical Education Teaching Efficacy Scale (PETES] 
(Humphries et al., 2012). The MBI consists of 22 items, divided into three subscales measuring three dimensions of burnout: emotional exhaustion, depersonalization, and a lowered sense of personal accomplishments. Each item is anchored to a 7-point scale which allows the respondent to express the frequency of experiencing a given symptom, ranging from 0 (never) to 6 (every day). Reliability of the tool was measured by a method of internal consistency with the use of the Cronbach alpha equation. Reliabilities of the sub-scales concerning a sense of personal accomplishments and emotional exhaustion were satisfactory, reaching Cronbach's $\alpha$ of 0.77 and 0.89 , respectively. The depersonalization subscale reached alpha values somewhat below the threshold of 0.60 which is considered as a limit of acceptable reliability, however such low values were also observed in more than 30 studies, including those aimed at preparing the Polish adaptation of MBI (Pasikowski, 2000). Therefore, according to Pasikowski (2000), relatively low reliability of the subscale may indicate some imperfection of the measure or may result from the specificity of the Polish population.

The PETES consists of seven subscales, each aimed at measuring one of the following dimensions of self-efficacy specific for teaching in PE: 1/ "Efficacy about PE content knowledge" (conviction that one possesses deep knowledge about various forms of physical activity and how to teach them, for example "I know a lot about fitness and can teach it effectively"), 2/ "Efficacy for applying scientific knowledge in teaching PE" (conviction that one is knowledgeable about developmental regularities of pupils, teaching motor skills, teaching standards etc., for example "I have a good grasp of exercise science concepts (from exercise physiology, biomechanics, motor learning and sport psychology), and can apply them to teaching physical education"), 3/ "Efficacy about accommodating skill level differences" (feeling efficient in addressing individualization problems, for example "If one of my students was having trouble with a drill, I know ways to change it to make it easier for them"), 4/ "Efficacy about teaching students with special needs" (knowing how to work with children with disabilities and impairments, for example "I know how to teach effectively a student with ADHD in my PE class"). 5/ "Efficacy about instruction" (efficacy in organizational, communicational and teaching skills, for example "I can use clear teaching clues that help students remember and understand how to do a skill correctly"), 6/ "Efficacy for using assessment"(being knowledgeable about applying assessment methods and principles in $\mathrm{PE}$, for example "My grades reflect how well students have learned what I wanted them to learn"), 7/ "Efficacy for using technology" (being acquainted with using technological aids having applications in motor learning, for example "I am aware of technology-based equipment and computer programs 
for PE, even if I don't have it"). Each item is accompanied by a 10-point scale from 1 - don't agree to 10 - agree. The measure was adapted by the use of the translation - back translation method and checked by the authors during a pilot study. All subscales were reliable, obtaining alpha values as follows: content knowledge 0.73, applying scientific knowledge in teaching PE 0.76, accommodating skill level differences 0.91 , teaching students with special needs 0.65 , instruction 0.83 , assessment 0.76 , using technology 0.84 .

\section{Data Analysis}

Descriptive statistics were shown as means and standard deviations. To assess the relationships between individual dimensions of burnout and teachers' self-efficacy stepwise regression analysis was used. All calculations were made in the Statistica 13.0 (Statsoft, PL) Software.

\section{Results of the Research}

Burnout syndrome among physical education teachers

Means of individual dimensions of burnout among PE teachers are shown in Table 1 . As it can be seen PE teachers can be described as moderately emotionally exhausted $(M=18.78, S D=6.79)$, moderately depersonalizing their students $(M=7.32, S D=4.67)$, but as having a high level of a decreased sense of personal accomplishments $(M=25.45, S D=2.90)$. The only statistical difference between female and male teachers was observed in emotional exhaustion, which was higher among female teachers, but one should bear in mind the low value of the effect size measure (Cohen's $d=0.23$ ) which suggests that the relationship between both variables is rather weak.

Table 1. Descriptive statistics (means and standard deviations) of burnout dimensions in PE teachers for the whole sample and separate for each sex

\begin{tabular}{lcccccccccc}
\hline & \multicolumn{2}{c}{ Total } & \multicolumn{2}{c}{ Female } & \multicolumn{2}{c}{ Male } & \multicolumn{3}{c}{ Difference female/male } \\
\cline { 2 - 11 } & $M$ & $S D$ & $M$ & $S D$ & $M$ & $S D$ & $t$ & $d f$ & $p$ & $d$ \\
\hline $\begin{array}{l}\text { Emotion } \\
\text { Exhaust }\end{array}$ & 18.78 & 6.79 & 19.66 & 6.80 & 18.09 & 6.72 & -2.30 & 399 & 0.022 & 0.23 \\
\hline Depers. & & & & & & & & & & \\
\hline Accompl & 25.32 & 4.67 & 7.36 & 2.84 & 7.28 & 2.95 & -0.28 & 399 & 0.783 & 0.03 \\
\hline
\end{tabular}


Since means do not always give a satisfactory picture of the examined population - at least due to their sensitivity to extreme results, which, depending on their location in the distribution, can overstate or understate the average values - a quantitative analysis was also performed. So, the numbers of teachers who met the criteria of a low, moderate and high level of particular dimensions of burnout were calculated (Pasikowski, 2004). The results of this analysis are shown in Table 2.

Table 2. The number and proportion of PE teachers meeting reference criteria of low, medium and high level of burnout in particular dimensions

\begin{tabular}{lcccccc}
\hline & \multicolumn{2}{c}{ Low burnout } & \multicolumn{2}{c}{ Moderate burnout } & \multicolumn{2}{c}{ High burnout } \\
\hline & $\mathbf{n}$ & $\%$ & $\mathbf{n}$ & $\%$ & $\mathbf{n}$ & $\%$ \\
\hline $\begin{array}{l}\text { Emotional } \\
\text { Exhaustion }\end{array}$ & 174 & $43.39 \%$ & 171 & $42.64 \%$ & 56 & $13.97 \%$ \\
\hline Depersonalization & 194 & $48.38 \%$ & 182 & $45.39 \%$ & 25 & $6.23 \%$ \\
\hline $\begin{array}{l}\text { Decresed Sense of } \\
\text { Accomplishments }\end{array}$ & 0 & $0 \%$ & 18 & $4.49 \%$ & 383 & $95.51 \%$ \\
\hline
\end{tabular}

Considering the abovementioned criteria, it was found that more than half of the PE teachers may be classified as at least moderately emotionally exhausted, and slightly more than 1 in 10 of them is highly exhausted. A slightly lower percentage of respondents was diagnosed as at least moderately burnt out in the dimension of depersonalization, although compared to the previously discussed group a smaller proportion of teachers was burned out to a high degree. Particularly noteworthy are the results referring to the last burnout dimensions - the reduced sense of personal accomplishments - where almost all the PE teachers surveyed reached high values on this dimension.

PE teachers' self-efficacy as a predictor of burnout

In order to reveal the relationships between the dimensions of burnout and self-efficacy a series of stepwise regression analyses were performed. Calculated for the entire sample all models were significant. The highest proportion of explained variance was found in the accomplishments dimension: $\mathrm{R}^{2}=0.10, \mathrm{~F}(2,398)=23.31$ $\mathrm{p}<0.001$, in which two kinds of self-efficacy turned out to be its significant predictors: concerning the application of scientific knowledge in teaching $\mathrm{PE}(\beta=0.23$, $\left.\mathrm{t}_{(398)}=4.33, \mathrm{p}<0.001\right)$ and about teaching students with special needs $(\beta=0.16$, $\left.\mathrm{t}_{(398)}=3.05, \mathrm{p}=.002\right)$. The emotional exhaustion model explained $7 \%$ of variance 
$\left(\mathrm{R}^{2}=0.07, \mathrm{~F}_{(4,398)}=7.64 \mathrm{p}<0.001\right)$ and significant predictors were: assessment efficacy $\left(\beta=-0.32, \mathrm{t}_{(396)}=-3.93, \mathrm{p}<0.001\right)$, accommodating skill level differences efficacy $\left(\beta=0.24, \mathrm{t}_{(396)}=3.12, \mathrm{p}=0.002\right)$ and using technology efficacy $(\beta=-0.15$, $\left.\mathrm{t}_{(396)}=-2.55, \mathrm{p}=0.011\right)$. The regression model for depersonalization was significant, but explained the smallest portion of variance $\left(\mathrm{R}^{2}=0.04, \mathrm{~F}_{(2,398)}=8.00 \mathrm{p}=0.002\right)$, with instructional efficacy being the only predictor of this dimension $(\beta=-0.27$, $\left.\mathrm{t}_{(396)}=-3.11, \mathrm{p}=0.002\right)$.

Performed separately for male and female teachers, regression analyses revealed some differences between them. Within the dimension of the emotional exhaustion model, parameters were as follows: $\mathrm{R}^{2}=0.08, \mathrm{~F}_{(2,221)}=9.10, \mathrm{p}<0.001$ for males and $\mathrm{R}^{2}=0.06, \mathrm{~F}_{(1,175)}=11.74, \mathrm{p}<0.001$ for females. In the former group significant predictors of burnout were efficacy assessment $\left(\beta=-0.38, \mathrm{t}_{(221)}=-4.26, \mathrm{p}<0.001\right)$ and accommodating skill level differences $\left(\beta=-0.24, \mathrm{t}_{(221)}=2.76, \mathrm{p}=0.006\right)$, in the latter group only efficacy in using technology $\left(\beta=-0.25, \mathrm{t}_{(175)}=-3.43, \mathrm{p}<0.001\right)$. No dimension of self-efficacy was related to depersonalization in male teachers $\left(\mathrm{R}^{2}=0.00\right.$, $\left.\mathrm{F}_{(3,220)}=2.04, p<0.110\right)$, which contrasted with results obtained for their female fellow teachers for whom the model was significant: $\mathrm{R}^{2}=0.10, \mathrm{~F}_{(3,173)}=6.75706$, $p<0.001$. Two of the self-efficacy categories were found to be significant predictors of the referred dimension of burnout: instruction efficacy $\left(\beta=-0.35, \mathrm{t}_{(173)}=-2.15\right.$, $\mathrm{p}<0.032)$ and content knowledge $\left(\beta=-0.34, \mathrm{t}_{(173)}=2.08, \mathrm{p}<0.039\right)$. Besides this, in the final model a third kind of self-efficacy appeared, applying scientific knowledge in teaching $P E$, with the $p$ value suggesting a trend towards significance $(\beta=-0.26$, $\left.\mathrm{t}_{(173)}=1.91, \mathrm{p}<0.058\right)$. The model for the third burnout dimension, decreased sense of professional accomplishments, was found to be significant both in males and females, respectively, $\mathrm{R}^{2}=0.11, \mathrm{~F}_{(2,221)}=13.381, \mathrm{p}<0.001$ and $\mathrm{R}^{2}=0.10, \mathrm{~F}_{(2,174)}=10.08$, $\mathrm{p}<0.001$. In both sexes two kinds of self-efficacy found their place in the final models: applying scientific knowledge in teaching PE and teaching students with special needs. However, while the former was a significant predictor in both sexes, (male teachers: $\beta=0.25, \mathrm{t}_{(221)}=1.91, \mathrm{p}<0.001$, female teachers: $\beta=0.21, \mathrm{t}_{(174)}=2.74$, $\mathrm{p}<0.007)$, the latter was a significant predictor of accomplishments in female teachers $-\left(\beta=0.18, \mathrm{t}_{(174)}=2.38, \mathrm{p}<0.018\right)$, while in males the $p$ reached a value showing a trend toward significance $-\beta=0.13, \mathrm{t}_{(221)}=1.87, \mathrm{p}<0.063$.

\section{Discussion}

The aim of the study was to reveal if there was a relationships between the self-efficacy of PE teachers and their professional burnout. It should be empha- 
sized that the construct of self-efficacy was measured in a way that stressed the specificity of the challenges met by PE teachers. We consider this fact as important, because this aspect has rarely been studied in this professional group, and in fact, preliminary database research (Sport Discuss, Academic Search Premier) showed no results for a combination of the keywords "physical education" AND teachers AND self-efficacy AND burnout.

Professional burnout of PE teachers as such, and its correlates as well, were studied by several authors. In Poland the problem was taken up for example by Brudnik (2010), who studied how burnout and self-efficacy were related, having found that in PE teachers the latter played a preventive role towards all three components of burnout, especially among male teachers, where correlation coefficients were stronger than in females. However, self-efficacy in her research was measured by the General Self-Efficacy Scale, which aimed to assess self-efficacy as a generalized sense, or personality trait, of being capable to solve various problems in life and reach personal goals, so "a situation-independent competence belief" (Scherbaum, Cohen-Charash, Kern, 2006: p.1084). Whereas, according to Bandura, self-efficacy is a construct that relates to particular kinds of tasks, and even particular tasks or situations. It is obvious that teachers as a whole face common challenges and obstacles, but it is also true that teachers of particular subjects face challenges and barriers that are unique for their specialization, and therefore self-efficacy in managing them should be measured accordingly. Therefore, a PE teachers' self-efficacy measure was created (Humphries et al., 2012) and used in our study. We have found that some dimensions of such specific PE teacher self-efficacy may serve as factors protecting them against burning out, although it should be honestly mentioned that the proportion of variance explained by the models with self-efficacy as a predictor of particular dimensions of burnout was quite small, not exceeding $10-11 \%$. What seems to be interesting, is that, while in most cases self-efficacy appeared to be a protective factor against burnout, one aspect of the former construct - namely "accommodating skill level differences efficacy" was positively related to emotional exhaustion of PE teachers. In other words, the more PE teachers felt efficacious in making efforts in meeting diversified abilities of students during PE classes, the greater was their risk of burning out. Considering that stronger efficacy beliefs in the reported area may result in greater activity of $\mathrm{PE}$ teachers in individualizing teaching, then a side effect of it may be a greater risk of being emotionally exhausted, probably because of being more strongly touched by differences that exist in the abilities, capabilities, fitness etc. of their pupils. The main "problem" of PE teachers seems to be their low sense of personal accomplishments, so feeling "undervalued", as this was diagnosed in nearly all respondents. In 
this regard two self-efficacy dimensions seem important "boosters" - the teachers' belief that they can successfully apply scientific knowledge in teaching PE and the belief that they can successfully face the challenges imposed by students with special educational needs, for example hyperactivity, touched by behavioural disturbances etc. To our surprise no other self-efficacies loaded the model, but on the other hand it may reflect the balanced preparation, or rather, looking at the low overall mean of the subscale, the unpreparedness of PE teachers, which is the reason why their within group diversification of results is low.

\section{Conclusions}

Therefore, even considering the fact that the amount of variance explained by all the models tested was relatively small, we consider strengthening efficacy perceptions of PE teachers as one of the goals in a broader set of strategies to prevent them from burning out in the teaching profession. The main problem that should be addressed is the sense of personal accomplishments, which was low in most of our respondents.

\section{References}

Aloe, A.M., Shisler, S.M., Norris, B.D., Nickerson, A.B. \& Rinker, T.W. (2014). Multivariate meta-analysis of student misbehaviour and teacher burnout. Educational Research Review, 12, 30-44.

Bandura, A. (1997). Self-efficacy: The exercise of control. New York: Freeman.

Bartholomew, K.J., Ntoumanis, N., Cuevas, R. \& Lonsdale C. (2014). Job pressure and ill-health in physical education teachers: The mediating role of psychological need thwarting. Teaching and Teacher Education, 37, 101-107.

Brown, C.G. (2012). A systematic review of the relationship between self-efficacy and burnout in teachers. Educational \& Child Psychology, 29, 47-63.

Brudnik, M. (2010). Macro-paths of burnout in physical education teachers and teachers of other general subjects. Studies in Physical Culture and Tourism, 4, 353-365.

Colakoglu, F.F. \& Yllmaz, T. (2014). Burnout levels of physical education teachers according to personal factors. Procedia - Social and Behavioral Sciences, 152, 409-414.

Hakanen, J.J., Bakker, A.B. \& Schaufeli, W.B. (2006). Burnout and work engagement among teachers. Journal of School Psychology, 43, 495-513.

Humphries, C.A., Hebert, E., Daigle, K. \& Martin, J. (2012). Development of a Physical Education Teaching Efficacy Scale. Measurement in Physical Education and Exercise Science, 16, 284-299. 
Maslach, C., Jackson, S.E. \& Leiter, M. (1996). Maslach burnout inventory manual, 3rd ed. Paolo Alto: Consulting Psychologists Press.

Oakes, W.P. et al (2013). Three-tiered models of prevention: Teacher efficacy and burnout. Education And Treatment of Children, 36, 95-126.

Pasikowski, T. (2004). Polska adaptacja kwestionariusza Maslach Burnout Inventory [Polish adaptation of the Maslach Burnout Inventory] In: H. Sęk (ed.) Wypalenie zawodowe przyczyny i zapobieganie [Professional burnout. Causes and prevention]. Warszawa: Wydawnictwo Naukowe PWN.

Savaş A.C., Bozgeyik Y. \& Eser I. 2014, A study on the relationship between teacher selfefficacy and burnout. European Journal of Educational Research, 3, 159-166.

Scherbaum, C.A., Cohen-Charash, Y. \& Kern, M.J. (2006). Measuring general self-efficacy - A comparison of three measures using item response theory. Educational and Psychological Measurement, 66, 1047-1063.

Skaalvik, E.M. \& Skaalvik, S. (2010) Teacher self-efficacy and teacher burnout: A study of relations. Teaching and Teacher Education, 26, 1059-1069. 